DOI 10.7764/ijanr.v48i3.2339

RESEARCH PAPER

\title{
Agriculture 4.0? Studying the evidence for automation in Chilean agriculture $^{1}$
}

\author{
Rodrigo Perez-Silva ${ }^{1}$, and Jorge Campos ${ }^{2}$ \\ ${ }^{1}$ Universidad Mayor, Center for Economics and Social Policy (CEAS). Manuel Montt 318, Providencia, \\ Chile, 7500628. \\ ${ }^{2}$ University of Reading, School of Agriculture, Policy and Development. Whiteknights PO Box 237, \\ Reading, RG6 6EU, UK.
}

\begin{abstract}
R. Perez-Silva, and J. Campos. 2021. Agriculture 4.0? Studying the evidence for automation in Chilean agriculture. Int. J. Agric. Nat. Resour. 233-247. In recent decades, computingbased technologies have been large contributors to the current digital and knowledge economy. This process has led to changes in the structure of employment and variations in relative wages across workers in skill distribution, with computing-based technologies representing the technological shift shaping current and future labor demand. In this regard, how job tasks might be replaced or complemented by computing-based technologies becomes a new and critical aspect in explaining how technological progress drives labor demand. Agriculture, as well as other sectors, has taken advantage of this technical progress, with emergent technologies contributing to the shift toward Agriculture 4.0. In the case of Chile, the evidence points to an overall reduction in the agricultural labor force and to an increase in the relative number of salaried workers within agriculture, particularly those in temporary jobs. However, nothing has been said about the types of tasks being performed in the sector, its evolution over time, and its relationship with automation. If agriculture is under a technological upgrading process, then we should expect the reduction in the number of salaried workers to be accompanied by an increase in the relative skillset of those still in the industry performing non-routine tasks. Contrary to what one might expect, our results suggest that the participation of routine tasks in agriculture has only increased over time, pointing to a low adoption of computing-based technologies compared to other economic sectors within the Chilean economy.
\end{abstract}

Keywords: Agriculture, automation, Chile, computing-based technologies, routinization.

\footnotetext{
${ }^{1}$ Investigation funded and sponsored by the Observatorio de Transformaciones Socioeconómicas (ANID/PCI/Max Planck Institute for the Study of Societies/MPG190012).
}

Received May 17, 2021. Accepted Nov 23, 2021

Corresponding author: rodrigo.perez@umayor.cl 


\section{Introduction}

Technology is a significant force driving labor demand and labor productivity (Autor et al., 1998). Its importance has become more critical, with new advancements based on computer-based technologies (e.g., information and communications technology [ICT], advanced software, automation) as important contributors to the current digital and knowledge economy. Additionally, these technologies contribute to economic growth, with the service economy rising while manufacturing and agriculture are falling. Since these changes are knowledge intensive rather than manual intensive, the demand for highly educated workers increases because of their skills and essential cognitive abilities needed to perform in the new technology-intense environment. Overall, computer-based technologies represent the modern technological change shaping current and future labor demand (Almeida et al., 2020). Further, how the task content of jobs might be replaced or complemented by automation has become a new and critical aspect in explaining how technological progress drives labor demand.

The agricultural sector has not been oblivious to the technological changes that have occurred in the economy. Agriculture has gone through different stages of technological development in its history, from what is known as Agriculture 1.0 (settled agriculture transitioning from hunting and gathering) to Agriculture 2.0 (the agricultural revolution in the 18 th century associated with the start of mechanization) to Agriculture 3.0 or the Green Revolution due to chemical fertilizers and improved high-yield crop introduction. Currently, Agriculture 4.0 refers to the use of emergent technologies (e.g., artificial intelligence [AI], the Internet of Things [IoT], sensors, and robotics, among others) as drivers leading the transformation and automation of agricultural practices (Rose \& Chilvers, 2018). These developments, although they have meant important increases in productivity, have also generated significant changes in the demand for employment and in the wages offered in agriculture (Rivera, 2019).

With this in mind, our objective was to document the trends of agricultural employment and its relation to the routinization of jobs in the agricultural sector. We did so by comparing these trends to those of other economic sectors in the Chilean economy as a way of testing for evidence of automation in agriculture. Using the task-based approach developed by Autor et al. (2003), we indirectly tested automation by classifying work tasks and documenting the evolution of the percentage of routine tasks carried out in agriculture vis-à-vis other sectors of the economy. This is, under the assumption that automation replaces routine-task jobs, an economic sector undergoing an automation process should present a relative reduction in the proportion of these types of tasks.

Simply put, a relative reduction in the participation of routine tasks within agriculture (relative to other economic sectors) would be suggestive of more intense use of computing-based technologies (e.g., automation) in the sector. However, as we will describe below, we could not directly test for computing-based technologies, but we observed trends in routinization between economic sectors over time and compared them to changes in agricultural employment and wages as an indirect test of automation in agriculture.

Before diving into the trends seen in agricultural employment and its potential association with routinization, it is important to briefly situate the sectoral trends and their contribution within the Chilean economy. The agricultural sector has grown, expanded and diversified its production and exports significantly in recent decades, contributing greatly to economic growth and poverty reduction in rural areas (Foster \& Valdés, 2006; Valderas et al., 2011). To that extent, Lopez and Anriquez (2004) and Anríquez and López (2007), among others, have shown that agricultural growth has produced an important reduction in poverty beyond the contribution that other economic 
sectors can exhibit. These studies indicate that an expansion of $4.5 \%$ in agricultural production generated a $7.3 \%$ reduction in poverty during the 1990 s, mainly characterized by improvements in jobs and wages. Fleming et al. (2010) found a similar outcome, suggesting that the international agricultural trade experienced by Chile in the late 1990s and early 2000s is associated with significant reductions in poverty.

This link between agricultural growth and poverty reduction is highly relevant to understanding the importance of agriculture in terms of its contribution to rural employment, especially of less-skilled workers. Thus, studying the level of automation proxied by routinization, its trends, and its potential impacts on the wages and employment of agricultural workers is relevant not only to this economic sector, but to the entire economy as well, since changes in the agricultural labor market can have additional impacts on rural-urban migration, rural development, and the national social protection policy if less-educated workers are displaced.

To that end, without pointing out with certainty the automation of jobs and the irruption of technology in agriculture as causes, the number of employees in the sector has declined consistently in recent years (Pérez et al., 2020). On the one hand, there have been significant changes in the distribution of income within the sector, which have tended to favor some groups of workers more than others. For example, between 1998 and 2017, the number of employees in agriculture fell by almost $14 \%$, with employers $(-55 \%)$ and self-employed workers $(-24 \%)$ being the groups where said reduction manifested with greater force. On the other hand, the salaries of employees, especially those in temporary jobs, are the ones that grew the most in the period, thus capturing a growing proportion of the income of the agricultural sector (Pérez et al., 2020; Valdés Alonso et al., 2008).

One reason for these changes in employment and in the distribution of income within agriculture could be related to the replacement of routine jobs by computer-based technologies and employment polarization (Autor et al., 2003; Goos \& Manning, 2007). The empirical support of such theories is the observation of increases in the number and salaries of those employees at the opposite margins of the distribution of skills; that is, those who are highly qualified, as well as those with lower qualifications. This phenomenon would be favored by the replacement of certain tasks and jobs based on the levels of routinization that they hold (Autor et al., 2003). In this framework, a routine task corresponds to an activity or function that can be expressed as a clear set of rules or instructions. In other words, a codable or programmable task would make it susceptible to being automated (Autor et al., 2003).

As a result, the labor market becomes polarized because medium-skilled occupations (operators, clerks or office workers, among others), often characterized as routine intensive, are replaced and automated. In contrast, occupations that are intensive in non-routine work, both cognitive (typically performed by highly skilled workers) and manual (typically performed by lower skilled workers), are less susceptible to automation (Acemoglu \& Autor, 2011; Autor et al., 2003). Thus, medium-skilled workers tend to move to less skilled jobs, competing and replacing some of their less-skilled counterparts within the same economic sector. However, technological changes affecting the labor market could not only produce changes in the structure of agricultural employment. Workers not only have the option to be employed in other jobs within agriculture, but can migrate to other sectors of the economy or migrate geographically to other parts of the country where such changes occur less quickly (Kekezi \& Boschma, 2021).

To put the effects of automation in perspective, Frey and Osborne (2017) concluded that 47\% of employment in the US had a high risk of becoming automated based on routinization indicators. For the case of Chile, CNP (2018) estimated that 
$61 \%$ of the country's employment has a medium and high risk of being automated, while Bravo et al. (2019) and the OECD (2019) determined that between 52 and $53 \%$ of employment is at risk of becoming automated in Chile. Interestingly, reports for Chile find that agriculture is one of the sectors with the highest risks of automation (Bravo et al., 2019; CNP, 2018).

In the Chilean agricultural sector and in the rest of the economy, if routine tasks are being replaced by current technological advances, then we can expect changes in the structure of employment. This is consistent with increases in wages and in the number of less skilled employees in non-routine and manual labor (for example, temporary workers). On the other hand, since highly skilled workers are complementary to technology (Acemoglu \& Autor, 2011; Autor et al., 2003), we can also see changes at the level of agricultural occupations related to the operation or management of tasks supported by precision agriculture machines or others that require higher degrees of qualification. Therefore, certain changes witnessed in the structure of agricultural employment, especially in reference to other sectors of the economy, could be associated and potentially explained by technological advances.

An indirect test of automation documents the evolution of the percentage of routine tasks carried out in agriculture vis-à-vis other sectors of the economy. This is, under the assumption that automation replaces routine-task jobs, an economic sector undergoing an automation process should present a relative reduction in the proportion of these types of tasks. Additionally, we can test whether these changes are associated with shifts in both the structure of employment and wages across economic sectors. Hence, despite this not being a direct finding of job automation, it makes it possible to show the consequences and changes linked to technological advances. This is especially true when compared to the rest of the economy within the same country.
Therefore, while agriculture may be one of the economic sectors with the highest risk of automation (Bravo et al., 2019; CNP, 2018) and there have been significant changes in the Chilean agricultural labor market-which are consistent with labor routinization and automatization - to the best of our knowledge, no previous attempt has been made to connect these labor market dynamics with automation in Chilean agriculture. Moreover, in addition to the existence of this missing link in the literature on Chilean agricultural economics, the agricultural sector is one of the chief employers of low-skilled workers, implying that the potential impacts of automation could be relevant in terms of job losses and wage reductions among the most vulnerable workers of the economy.

To that end, we not only describe the agricultural risk of automation and its trend over time; we also provide a comparative view of the phenomenon by contrasting its results with those of the other economic sectors in the Chilean economy. Thus, we have attempted to shed some light on one of the potential causes of labor market dynamics in a highly relevant economic sector, and to inform agricultural and rural development policies in Chile.

We employed the CASEN survey from 1992 to 2017 and the Chilean Classifier of Occupations (INE, 2008) to document changes in the structure of the labor force and to characterize occupations according to the level of routine intensity across industries. Unlike previous evidence, our main results signal that, whereas agriculture exhibits low levels of routinization compared to other industries, over time, the routine intensity of the tasks performed in agriculture has grown significantly more than it has in other sectors of the economy. These results denote that agriculture has a low level of technology adoption, and still strongly relies on manual labor to perform the relevant activities. This is, at least for the case of Chile, a different story to the one usually talked about agriculture being at a high risk of becoming automated. 
The rest of the paper is organized as follows. Section 2 describes the data and methods used, providing details about the classification of tasks and the automation risk across economic sectors. Section 3 presents the main results, and Section 4 concludes and offers policy recommendations and avenues for future research, specifically for the case of Chilean agriculture.

\section{Data and methods}

Our main source of information was the CASEN household survey, specifically the versions of 1992, 1996, 2000, 2006, 2009, 2013, and 2017. Since 1987, the CASEN survey has been a nationally representative survey intended to gather information about income, employment, education, and other demographics for all Chilean administrative regions and zones (both urban and rural). The CASEN survey is the primary instrument used to measure poverty levels and to help design public policy in Chile. For the 2017 version, the latest survey we employed for this manuscript, the sample size was 70,948 households and 216,439 individuals (approximately $1.2 \%$ of the total population).

We were unable to cover a broader period (e.g., the 1980s) since the data are not available before 1990. Similarly, because of the Chilean social unrest of 2019 and the COVID-19 pandemic, CASEN released only one more version after 2017 (CASEN 2020), but it is a reduced version of the survey with fewer questions, a smaller sample, and a different methodology. Hence, for comparability reasons, we focused only on the period for which we have reliable data.

Additionally, we used the Chilean Classifier of Occupations prepared by the National Institute of Statistics (INE, 2018) to characterize occupations according to the level of routine intensity observed in the tasks that make up a given occupation. As such, we combined these two sources of secondary data to gauge changes in employment according to the job's task content.
On the one hand, from CASEN, we estimated changes in employment structure. On the other hand, we relied on the task descriptions for occupations documented in the Chilean Classifier of Occupations. As a result, we built task-content measures at the occupational group level, percentage shares, and an intensity index, following specialized literature about the relationship between technology and a job's task content (e.g., Autor et al., 2003; Autor et al., 2003; Autor \& Dorn, 2013; Goos et al. 2014).

The estimation of the task content of occupations includes three stages. First, we classified the activities or functions of each group into the categories proposed by Autor et al. (2003). Second, we added the 2-digit CASEN information and calculated the number of employed persons in each occupational group for each year. The third stage corresponds to the construction of an index, which represents the grouped task content of each economic sector for every year observed.

To evaluate the task content of occupations, we used the descriptions of tasks documented in the Chilean Classification of Occupations, CIUO08CL (INE, 2018), which is based on the current International Standard Classification of Occupations, ISCO-08 (ILO, 2012). The 44 occupational groups of CIUO08-CL are homologous to the 27 occupational groups observed in CASEN, with the exception of those related to the armed forces and law enforcement. ${ }^{2}$

Typically, all these classifications code occupations as 1-, 2-, 3-, and 4-digits groups to represent major, sub-major, minor, and unit groups, respectively. To illustrate, Table 1 presents an example of the structure and associated tasks for a case in CIUO88.

\footnotetext{
${ }^{2}$ For 1988, CASEN used the ISCO-88 classification. Therefore, we needed to carry out a standardization procedure between ISCO08-CL and ISCO-88 using the correspondence tables published by (OIT, 2005).
} 
Table 1. Example of CIUO88 structure

\begin{tabular}{|c|c|c|c|}
\hline Groups & Codes & Occupational groups & Task descriptions \\
\hline Major group & 2 & Professionals & $\begin{array}{l}\text { Conducting research and analysis, concept development, the } \\
\text { application of science-related knowledge, the provision of various } \\
\text { companies, legal and social services }\end{array}$ \\
\hline $\begin{array}{l}\text { Sub-major } \\
\text { group }\end{array}$ & 21 & $\begin{array}{l}\text { Professionals in the physical, } \\
\text { chemical, and mathematical } \\
\text { sciences and engineering }\end{array}$ & $\begin{array}{l}\text { Investigate, apply, or advise on scientific knowledge related to } \\
\text { physical phenomena, chemical processes, and mathematical, } \\
\text { statistical and computer methods; project and direct the construction } \\
\text { of buildings, public works, cities and transit systems and structures, } \\
\text { among others }\end{array}$ \\
\hline Minor group & 213 & IT professionals & $\begin{array}{l}\text { Evaluation, planning, and design of hardware or software } \\
\text { configurations for specific applications; design, writing and } \\
\text { maintenance of software for specific requirements, consulting with } \\
\text { users }\end{array}$ \\
\hline Unit groups & 2132 & Computer programmers & $\begin{array}{l}\text { Consult with users to formulate document requirements, identify and } \\
\text { analyze business processes, make recommendations to companies } \\
\text { and system functionalities }\end{array}$ \\
\hline
\end{tabular}

Source: ISCO88 (ITO, 2005)

We analyzed the task content for the sub-major occupational groups (2 digits) on the basis of aggregating the minor groups (3 digits). This implies analyzing and classifying 846 activities or functions (803 unique) into five categories: cognitive routine, analytical non-routine, interactive non-routine, manual routine, and manual non-routine (Autor et al., 2003; Mihaylov \& Tijdens, 2019; Spitz-Oener, 2006). Table 2 presents some examples of tasks and the respective category.

We then computed the relative importance of each category at the level of occupation, calculating the proportion of work activities for a given category over the total number of tasks. As a result, we obtained five intensity measurements according to the types of tasks that characterize each occupational group. This is summarized in Eq. (1):

$$
T P_{i, j}=\frac{n_{i, j}}{n_{j}}
$$

where $T P_{i, j}$ is the proportion of tasks that belong to task category $i$ (cognitive routine, analytical non-routine, interactive non-routine, manual routine, and manual non-routine) in each of the $27 j$ -occupational groups. $n_{i, j}$ is the number of tasks in the $i$ th -category of occupation $j$, and $n_{j}$ is the total tasks of occupation $j$. Thus, for each occupation, we had five metrics, with ranges between 0 and 1 , to measure the variation in routine intensity of a given category across all occupations.

Since our analysis centered on the routine aspect of task content, we constructed an indicator $\left(I I R_{j}\right)$ that adds the proportions of cognitive and manual routine tasks from Eq. (1). We performed this analysis under the (potentially strong) assumption that the task content of occupations remains constant over time (Reijnders \& de Vries, 2018).

To facilitate the analysis, we added a variable that categorizes the occupations according to the degree of routine using the value observed for the $I I R_{j}$ based on the following thresholds: 0 to 0.4 for low; between 0.40 and 0.75 for medium; and between 0.75 and 1 for high (CNP, 2018; Frey \& Osborne, 2017). This categorization is usually related to the degree of automation to which an occupation would be exposed; therefore, it is also known as automation risk (Frey \& Osborne, 2017; Rivera, 2019). 
Table 2. Task focus categories

\begin{tabular}{|c|c|}
\hline Task Categories & Examples \\
\hline Non-routine analytical & $\begin{array}{l}\text { Research, analysis, evaluation, forecasting, prognosis, monitoring and control, examining patients, } \\
\text { creativity, application of knowledge, and staff evaluations, among others }\end{array}$ \\
\hline Non-routine interactive & $\begin{array}{l}\text { Advice, consultancy, teaching, training, supervising, directing, leading, collaborating, testifying in } \\
\text { court, interviewing, obtaining information, representing individuals or organizations, and selecting } \\
\text { personnel, among others }\end{array}$ \\
\hline Cognitive routine & $\begin{array}{l}\text { Preparing invoices and receiving payments, operating cash registers and office computer } \\
\text { equipment, conducting tests, inspection and quality control, reading work orders, recording and } \\
\text { processing information, reviewing the accuracy and integrity of records and documents, the } \\
\text { secretariat, and making inventories, among others }\end{array}$ \\
\hline Non-routine manual & $\begin{array}{l}\text { Crafts and handwork, artisan baking, carpentry, tailoring, operating non-stationary machines } \\
\text { and mobile equipment (cranes, excavators), driving vehicles, cooking, serving food, cleaning, } \\
\text { hairdressing, surveillance, protection, repair, elderly care and care of minors, installation of } \\
\text { machinery and equipment, and raising animals and plants, among others }\end{array}$ \\
\hline
\end{tabular}

Source: Own elaboration based on the Chilean Classification of Occupations CIUO08-CL (INE, 2018) and CASEN

In the CASEN survey, occupations are identified at the 4-digit level. Therefore, we added the data to 2 digits to obtain the sub-major groups. Once we identified the 27 sub-main groups, we computed the participation of each occupation in total sectoral employment (TEP). Then, we multiplied it by the IIR term to estimate an indicator of intensity from routine at the industry level, which we call IIRE. Therefore, IIRE corresponds to the weighted sum of TEP for each occupation, with $I I R$ acting as a weight, as follows:

$$
I R R E_{j}=\sum\left(T E P_{j, k, t} * I R R_{j}\right)
$$

where $I I R E_{j}$ is the routine intensity index of each economic sector. Since $I I R E_{j}$ is a sum of products between proportions, its value will be between 0 and 1 , where values close to 0 (1) refer to industries with low (high) proportions of routine-intensive occupations and tasks. This allowed us to observe the composition and evolution of the agricultural labor force in terms of the intensity of routine tasks relative to the rest of the industries in the economy.

\section{Results}

The analysis of the task content for each of the 27 occupational groups is summarized in Table 3. The first and second columns refer to the code and name of the occupation, while the next five columns refer to the proportions of each type of task. The Routine Index [RII] column corresponds to the sum of the proportions of routine tasks present in the occupation, both cognitive and manual, while the Degree of Routine column classifies occupations as having a high, medium, and low degree of routine intensity.

Given that the occupations are ordered from the highest to the lowest RII, in the first three rows, it is possible to appreciate those occupations with high routine intensity; that is, at least $75 \%$ of routine tasks. Thus, while "customer service clerks" and "office clerks" are intensive in cognitive routine tasks, "machine operators and assemblers" are intensive in manual routine tasks. In the case of occupations with medium degrees of routinization, there may be cases where the proportions 
Table 3. Task content of the 27 main sub-groups in the 2-digit CIUO88, based on the task analysis of the Chilean Classifier of Occupations for 2008 (INE, 2018). (Order of occupations from highest to lowest routine index. RII = Routine Intensity Indicator)

\begin{tabular}{|c|c|c|c|c|c|c|c|c|}
\hline \multicolumn{3}{|c|}{ Sub-major occupation groups CIUO88 } & \multicolumn{4}{|c|}{ Task proportions by task category } & \multirow[b]{2}{*}{ RII } & \multirow[b]{2}{*}{$\begin{array}{l}\text { Degree of } \\
\text { routine }\end{array}$} \\
\hline Code & Name & $\begin{array}{l}\text { Analytical } \\
\text { non-routine }\end{array}$ & $\begin{array}{l}\text { Interactive } \\
\text { non-routine }\end{array}$ & $\begin{array}{l}\text { Cognitive } \\
\text { routine }\end{array}$ & $\begin{array}{l}\text { Manual } \\
\text { routine }\end{array}$ & $\begin{array}{l}\text { Manual } \\
\text { non- } \\
\text { routine }\end{array}$ & & \\
\hline 42 & Customer service clerks & 0.000 & 0.095 & 0.857 & 0.048 & 0.000 & 0.905 & High \\
\hline 82 & $\begin{array}{l}\text { Machine operators and } \\
\text { assemblers }\end{array}$ & 0.000 & 0.040 & 0.140 & 0.740 & 0.080 & 0.880 & High \\
\hline 41 & Office clerks & 0.000 & 0.121 & 0.879 & 0.000 & 0.000 & 0.879 & High \\
\hline 81 & $\begin{array}{l}\text { Stationary plant and related } \\
\text { operators }\end{array}$ & 0.068 & 0.205 & 0.295 & 0.273 & 0.159 & 0.568 & Medium \\
\hline 34 & Other associate professionals & 0.127 & 0.380 & 0.451 & 0.000 & 0.042 & 0.451 & Medium \\
\hline 73 & $\begin{array}{l}\text { Precision, handicrafts, printing } \\
\text { and related Trade workers }\end{array}$ & 0.074 & 0.111 & 0.185 & 0.259 & 0.370 & 0.444 & Medium \\
\hline 93 & $\begin{array}{l}\text { Laborers in mining, } \\
\text { construction, manufacturing, } \\
\text { and transport }\end{array}$ & 0.000 & 0.000 & 0.000 & 0.333 & 0.667 & 0.333 & Low \\
\hline 74 & $\begin{array}{l}\text { Other craft and related trade } \\
\text { workers }\end{array}$ & 0.097 & 0.000 & 0.032 & 0.226 & 0.645 & 0.258 & Low \\
\hline 31 & $\begin{array}{c}\text { Physical and engineering } \\
\text { science associate professionals }\end{array}$ & 0.366 & 0.268 & 0.244 & 0.000 & 0.122 & 0.244 & Low \\
\hline 61 & $\begin{array}{l}\text { Market-oriented, skilled } \\
\text { agricultural and fishery workers }\end{array}$ & 0.096 & 0.231 & 0.154 & 0.077 & 0.442 & 0.231 & Low \\
\hline 52 & $\begin{array}{l}\text { Models, salespersons, and } \\
\text { demonstrators }\end{array}$ & 0.000 & 0.435 & 0.217 & 0.000 & 0.348 & 0.217 & Low \\
\hline 71 & $\begin{array}{c}\text { Extraction and building trade } \\
\text { workers }\end{array}$ & 0.000 & 0.120 & 0.080 & 0.120 & 0.680 & 0.200 & Low \\
\hline 32 & $\begin{array}{l}\text { Life science and health } \\
\text { associate professionals }\end{array}$ & 0.333 & 0.214 & 0.095 & 0.071 & 0.286 & 0.167 & Low \\
\hline 72 & $\begin{array}{l}\text { Metal, machinery and related } \\
\text { trade workers }\end{array}$ & 0.050 & 0.050 & 0.100 & 0.050 & 0.750 & 0.150 & Low \\
\hline 13 & General managers & 0.533 & 0.333 & 0.133 & 0.000 & 0.000 & 0.133 & Low \\
\hline 33 & $\begin{array}{c}\text { Teaching associate } \\
\text { professionals }\end{array}$ & 0.125 & 0.625 & 0.125 & 0.000 & 0.125 & 0.125 & Low \\
\hline 62 & $\begin{array}{l}\text { Subsistence agricultural and } \\
\text { fishery workers }\end{array}$ & 0.029 & 0.059 & 0.000 & 0.118 & 0.794 & 0.118 & Low \\
\hline 51 & $\begin{array}{c}\text { Personal and protective service } \\
\text { workers }\end{array}$ & 0.000 & 0.250 & 0.083 & 0.033 & 0.633 & 0.117 & Low \\
\hline 92 & $\begin{array}{c}\text { Agricultural, fishery, and related } \\
\text { laborers }\end{array}$ & 0.000 & 0.000 & 0.000 & 0.111 & 0.889 & 0.111 & Low \\
\hline 23 & Teaching professionals & 0.390 & 0.512 & 0.098 & 0.000 & 0.000 & 0.098 & Low \\
\hline 24 & Other professionals & 0.490 & 0.449 & 0.061 & 0.000 & 0.000 & 0.061 & Low \\
\hline 83 & $\begin{array}{l}\text { Drivers and mobile plant } \\
\text { operators }\end{array}$ & 0.000 & 0.000 & 0.000 & 0.056 & 0.944 & 0.056 & Low \\
\hline 91 & $\begin{array}{c}\text { Sales and services, elementary } \\
\text { occupations }\end{array}$ & 0.000 & 0.316 & 0.026 & 0.026 & 0.632 & 0.053 & Low \\
\hline 12 & Corporate managers & 0.367 & 0.582 & 0.051 & 0.000 & 0.000 & 0.051 & Low \\
\hline 22 & $\begin{array}{l}\text { Life science and health } \\
\text { professionals }\end{array}$ & 0.535 & 0.372 & 0.047 & 0.000 & 0.047 & 0.047 & Low \\
\hline 21 & $\begin{array}{c}\text { Physical, mathematical, } \\
\text { and engineering science } \\
\text { professionals }\end{array}$ & 0.821 & 0.154 & 0.026 & 0.000 & 0.000 & 0.026 & Low \\
\hline 11 & Legislators and senior officials & 0.444 & 0.556 & 0.000 & 0.000 & 0.000 & 0.000 & Low \\
\hline
\end{tabular}

Source: Own elaboration based on the Chilean Classification of Occupations CIUO08-CL (INE, 2018). 
of routine cognitive and routine manual tasks are similar; for example, "Stationary-Plant and related Operators," while other occupations showed dissimilar proportions between these types of tasks.

Most occupations were concentrated in what we classify as a low degree of routine (21 of the 27 groups analyzed), with IIR values above $33 \%$ for occupations such as "laborers in mining, construction, manufacturing, and transport," and those close to 0 in occupations related to exact sciences such as "physical, mathematical and engineering science professionals" (2.6\%). At the lower end, with $0 \%$ routine, are occupations grouped into "legislators and senior officials." This information, although it focuses on occupations and not directly on the sectors of the economy, allowed us to infer that the tasks typically carried out in agriculture are not part of those that have a greater relative risk of automation, given the low levels of routine in jobs.

Occupations that are expected to be more represented in the agricultural sector-such as "market-oriented skilled agricultural and fishery workers," "subsistence agricultural and fishery workers," and "agricultural, fishery and related laborers" - cover a maximum of $23 \%$ of routine tasks. Therefore, in the aggregate and compared analysis at the level of the economic branch, agriculture could result as an activity with a low level of routinization; therefore, its workforce could be less susceptible to becoming automated. In addition, when observing that the predominant type of task in these occupations is that of a non-routine manual nature, then susceptibility is even lower. This is because activities typically developed by these groups, such as raising animals and implementing the tasks of crops, are not easily codifiable or programmable, as happens in other economic sectors.

That is, while the activities carried out in agriculture require a relatively low qualification, the specific tasks performed appear not to be routine intensive and thus have a lower relative risk of becoming automated (compared to other sectors of the economy). This is important since, as previously observed, it is consistent with a significant growth in the participation of those employed in temporary jobs within the agricultural sector in recent decades. These workers could be carrying out non-routine manual tasks, which are difficult to automate. On the other hand, the drop in the number and participation of workers in the other occupation categories (mostly employers and self-employed workers) could be explained by the replacement of high-skilled jobs with machinery and computers, which tend to affect more workers at the rightward end of the skill distribution.

This is consistent with the appearance of technological changes aimed at replacing higher-skilled jobs within the agricultural sector (e.g., the emergence of software) but with a low capacity to replace more labor-intensive tasks. Thus, although at a general level both the number of employees and agricultural workers has fallen, such reductions are more pronounced among workers who are potentially more qualified and much less accentuated on workers performing manual labor.

The identification of the occupational groups in CASEN makes it possible to estimate the number of workers employed in each of these groups. Thus, from the analysis of task content, we estimated these frequencies based on the degree of routine, according to the economic sectors of interest. Table 4 summarizes this information for 1992 and 2017, as well as for a subset of productive activities, in addition to the agricultural sector.

From Table 4, it is possible to observe, on the one hand, the composition of the labor force according to the degree of routine of the occupations that compose it and the changes between 1992 and 2017. In relative terms, low-routine occupations are the majority in each of the productive activities examined. Thus, an initial observation of Table 4 leads us to conclude that only two sectors of the economy have seen a reduction in the number of persons employed. These are agriculture (where the 
Table 4. Number of employed persons in the thousands, according to the Degree of Routine for a subset of economic sectors, CASEN 1992 and 2017

\begin{tabular}{|c|c|c|c|c|}
\hline \multirow{2}{*}{$\begin{array}{l}\text { Economic sector, year, and } \\
\text { growth }\end{array}$} & \multicolumn{3}{|c|}{ Number of employed workers by Degree of Routine } & \multirow{2}{*}{ Total } \\
\hline & High & Medium & Low & \\
\hline \multicolumn{5}{|l|}{ Agriculture } \\
\hline 1992 & 16.0 & 5.8 & 752.7 & 774.6 \\
\hline 2017 & 26.6 & 9.5 & 681.5 & 717.5 \\
\hline Growth 2017/1992 & $66 \%$ & $62 \%$ & $-9 \%$ & $-7 \%$ \\
\hline \multicolumn{5}{|l|}{ Construction } \\
\hline 1992 & 13.2 & 8.6 & 410.8 & 432.5 \\
\hline 2017 & 22.2 & 18.7 & 658.4 & 699.4 \\
\hline Growth $2017 / 1992$ & $69 \%$ & $119 \%$ & $60 \%$ & $62 \%$ \\
\hline \multicolumn{5}{|l|}{ Mining } \\
\hline 1992 & 11.0 & 7.1 & 86.7 & 104.8 \\
\hline 2017 & 7.6 & 17.4 & 113.3 & 138.4 \\
\hline Growth 2017/1992 & $-31 \%$ & $146 \%$ & $31 \%$ & $32 \%$ \\
\hline \multicolumn{5}{|l|}{ Manufacturing } \\
\hline 1992 & 130.1 & 98.8 & 593.7 & 822.7 \\
\hline 2017 & 130.6 & 80.2 & 522.9 & 733.7 \\
\hline Growth 2017/1992 & $0 \%$ & $-19 \%$ & $-12 \%$ & $-11 \%$ \\
\hline \multicolumn{5}{|c|}{ Transport and communications } \\
\hline 1992 & 40.5 & 11.1 & 289.8 & 341.4 \\
\hline 2017 & 70.6 & 26.3 & 467.5 & 564.4 \\
\hline Growth $2017 / 1992$ & $74 \%$ & $137 \%$ & $61 \%$ & $65 \%$ \\
\hline
\end{tabular}

Source: Own elaboration based on the Chilean Classification of Occupations CIUO08-CL (INE, 2018) and CASEN.

number of employed workers fell by $7 \%$ between 1992 and 2017) and manufacturing (where in the same period, the number of employed workers fell by $11 \%$ ). In contrast, employment increased significantly in transport and communications, construction, and mining. To this extent, employment, at the aggregate level, has been concentrated in typically less labor-intensive economic sectors.

Alternatively, in the case of agriculture and in manufacturing, the jobs "lost" are located among workers who performed a lower proportion of routine tasks. In contrast, it seems that over time, occupations and jobs have become increasingly concentrated around workers performing routine tasks. This is the opposite of what would be expected for economic sectors that have initiated automation processes, but it is consistent with technology that has sought to replace tasks usually performed by workers with higher relative qualifications.

In sum, Table 4 shows that agriculture and manufacturing have witnessed the routinization of tasks, while in the rest of the Chilean economy, tasks with medium levels of routine have tended to grow. The extreme case of this difference is posed by the mining sector, where workers in occupations with a high proportion of routine tasks have begun to disappear.

The estimation of the IIRE is presented graphically in Figure 1 for agriculture and other economic sectors. As mentioned earlier, the IIRE takes values 
between 0 and 1 , with 0 referring to economic sectors with low proportions of occupations in routine tasks, and 1 to economic sectors in which there is a large share of routine-intensive tasks. In terms of magnitude, values in the range 0.16 to 0.18 are seen in agriculture during the period analyzed, placing it as one of the economic sectors with less routine intensity. The rest of the activities reveal values that start from 0.19 , and reach values of approximately 0.37 , as in the case of the years 1996 and 2000 in manufacturing.

However, in terms of evolution over time, and as stated in the previous results, the agricultural sector shows notable growth of the indicator, which would imply that it is an activity that has increased its levels of routinization in the last few decades. In contrast, the remaining activities exhibit clear decreases, with the exception of transportation and communications, where although the indicator falls, this decrease is noticeable only at the end of the period.

Similarly, although it is true that only in agriculture does the intensity of routine tasks seem to rise over time, a decrease in routine levels is clearly noted only in the electricity, gas and water sectors; financial and insurance establishments; manufacturing industries; and the exploitation of mines and quarries, at least in the last two periods.

From the analysis of the IIRE indicator, we could say that the occupational structure in agriculture may be characterized by a higher share of medium-skilled occupations, which are typically intensive in routine tasks. On the one hand, this could be the effect of the movement of these workers from other activities where they are being displaced as a result of technological change biased toward routine tasks. Similarly, the greater modernization in agriculture could be affecting the need to incorporate medium-skilled laborers, who would be operating equipment or performing administrative tasks, which typically correspond to routine tasks.

Thus, our results indicate that agriculture, compared to other economic sectors, has a relatively low level of routinization and less routine-intensive

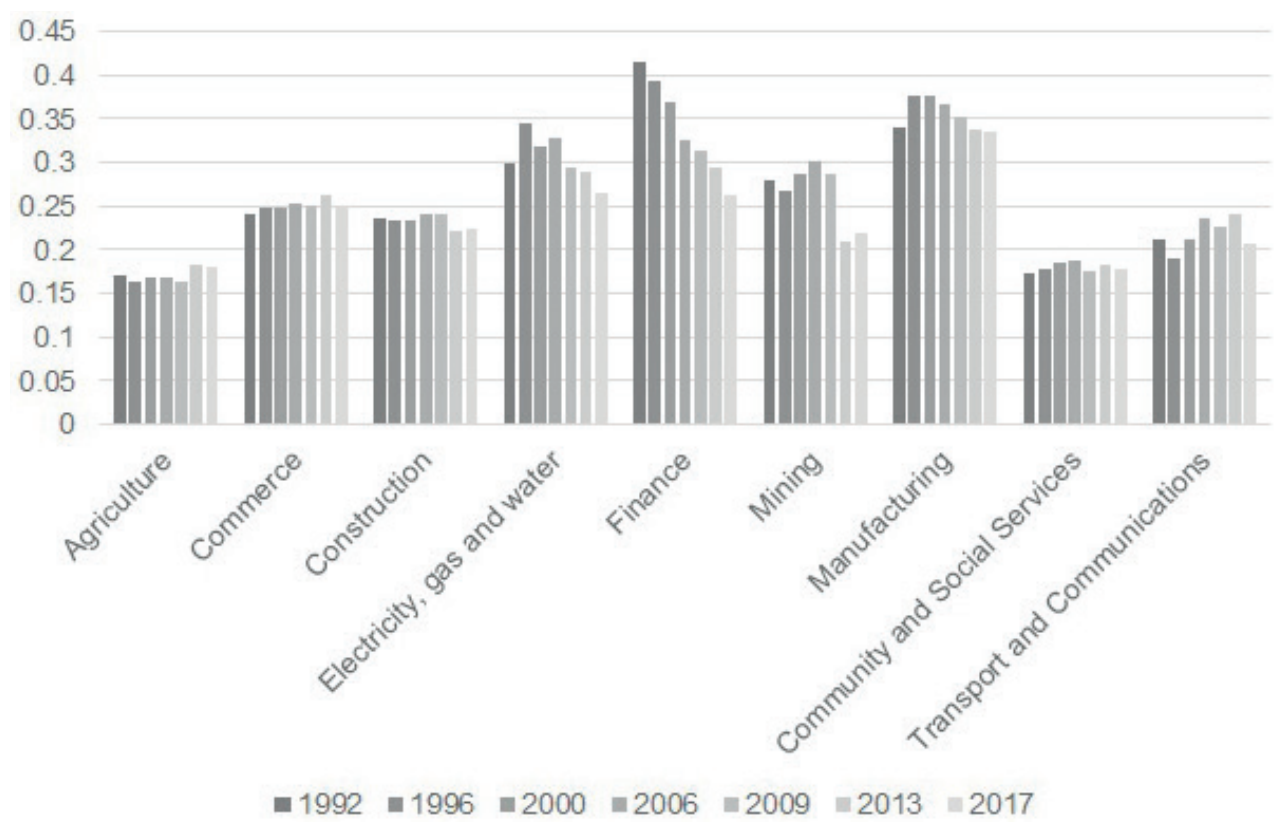

Figure 1. Routine Intensity Index by Economic Sector, IIRE, for 1992-2017. 
occupations and workers. This would suggest that automation processes occurring in the Chilean economy are probably more effective when happening in other economic sectors (such as finance, manufacturing and electricity, gas and water, and industries with high levels of routine tasks). Nonetheless, agriculture is the only economic sector (perhaps with community and social services and with transport and communications) in which the proportion of routine-intensive tasks has been increasing over time.

Overall, these findings imply that the risk of automation is low for agriculture compared to other economic sectors, and moreover that changes in the labor market are not supportive of automation being an important issue in Chilean agriculture, at least not in the last few decades.

To be more precise, our results contradict previous evidence denoting that agriculture is at high risk of becoming automated. Not only are routine levels low in agriculture; they have also risen over time, suggesting a relatively low adoption of technologies and replacement of workers in routine tasks. To that end, agriculture, unlike most of the other sectors in the Chilean economy, can still be seen as a refuge for less-educated workers. However, in the long run, a shortage of less-skilled workers, coupled with an increase in routine tasks, could lead to a drastic shift in automation in agriculture, especially if wages are increasing beyond workers' productivity in the short term.

\section{Conclusions}

Agriculture, like all other sectors of the economy, has been exposed to technological advances that threaten the replacement of workers and increase the number of unemployed people. The international evidence primarily tends to sustain that such advances favor workers located at the extremes of the distribution of qualifications to the detriment of those with medium qualifications, who perform more routine tasks and are more easily replaceable by machinery, software and other technological advances. In the same way, the evidence supports that we can expect to find a greater dispersion of income within the economy, since there would be productive increases among workers who are more easily complemented by technology, and on the other hand, competition for jobs that require relatively low qualifications.

The evidence presented for Chile, and specifically for the case of agriculture, seems to tell a different story. First, agricultural tasks, unlike tasks in other economic sectors, seem to be not very routine-intensive; therefore, the sector as a whole displays a relatively low risk of automation. Second, not only has the number of highly routine tasks not been reduced in agriculture, but this figure rose considerably between 1992 and 2017. Likewise, low routine occupations have been reduced in the sector. In other words, agriculture has become "routinized" over time, following the opposite trend to the rest of the economy, which has moved toward less routine jobs and occupations. Consequently, at the aggregate level (and although with certain minor ups and downs), agriculture represents the only sector of the economy that demonstrates an upward trend in the routine intensity index.

The information presented is consistent with reductions observed in the number of employees in agriculture, but with a relative increase in the number and income received by less-qualified workers within the sector, something that has previously been highlighted in the literature for the Chilean case (e.g., Anríquez et al., 2016).

On the other hand, agriculture, and to a certain extent manufacturing activity, can provide the greatest refuge for less-skilled workers who have potentially been displaced from other sectors of the economy. Both this movement between economic sectors and the competition that may be generated by non-routine manual labor-toward which workers with higher relative qualifications 
could be moving (in the middle of the distribution of skills) —-would be interesting to study in subsequent research.

Importantly, we did not directly evaluate the effects of automation, but rather inferred its effects from the dynamics observed in the labor market and the tasks performed in each sector of the economy. A more detailed analysis of this process, which is beyond the scope of this manuscript, would be necessary to effectively assign causality to the phenomenon.

The question to be asked is what can (or should) the agricultural sector and politics do in the face of the changes witnessed? Is it a cause for concern that agriculture is one of the few sectors of the economy where work has become relatively more routine over time, as opposed to the rest of the economy? In principle, it is expected that if the number of routine tasks rises, this may have effects on employment, which should increase for those with relatively low qualifications. On the other hand, it would be interesting to know if these dynamics have produced increases in the sector's productivity. Is it more efficient for the agricultural sector to replace skilled workers and increase the pool of less skilled workers? If so, is it sustainable in the long run, and what are the experiences of countries that compete with Chile in international markets?

The evidence presented here, added to the already known declines in competitiveness on the part of the Chilean agro-export sector (see, for example, Pérez \& Valdés, 2019), as well as the employment dynamics in the sector, allow us to assume that the agricultural sector is losing momentum and that this could have adverse impacts in the medium and long term. In this sense, the development strategy should be oriented toward investments in research and development (R\&D); the creation of alliances among private and public actors, universities, and national and international research centers; and the generation of knowledge to improve productive processes and thus boost the sector's competitiveness. Promoting less routinization in the sector and increasing the number of non-routine cognitive tasks will not only help the sector itself but can also strengthen local economies and rural areas and smaller urban centers where agricultural activity takes place.

\section{Resumen}

R. Perez-Silva, y J. Campos. 2021. ¿Agricultura 4.0? Estudiando la evidencia de la automatización en la agricultura chilena. Int. J. Agric. Nat. Resour. 233-247. En las últimas décadas, los avances tecnológicos basados en Tecnologías de la informacion y Comunicaciones, TIC, han contribuido en gran medida a la actual economía digital y del conocimiento. Este proceso ha dado lugar a cambios en la estructura del empleo, variaciones en los salarios relativos entre trabajadores y en la distribución de habilidades debido a que estas nuevas tecnologías representan la mayor parte del cambio tecnológico que configura la actual y futura demanda laboral. En este sentido, la forma en que las tareas que caracterizan las ocupaciones laborales pueden ser reemplazadas o complementadas por tecnologías TIC y similares, es un aspecto nuevo y crítico para explicar cómo el progreso tecnológico impulsa la demanda laboral. La agricultura, al igual que otros sectores, se ha beneficiado de este progreso técnico, con tecnologías emergentes que contribuyen al cambio hacia la Agricultura 4.0. En el caso de Chile, la evidencia apunta a una reducción general de la fuerza laboral agrícola y a un aumento en el número relativo de trabajadores asalariados dentro de la agricultura, particularmente aquellos en trabajos temporales. Sin embargo, poco se ha dicho sobre el tipo de tareas que se realizan en el sector, su evolución en el tiempo y su relación con la automatización. Si la agricultura 
se encuentra en un proceso de actualización tecnológica, entonces deberíamos esperar que la reducción en el número de trabajadores asalariados vaya acompañada de un aumento en el conjunto de habilidades relativas de aquellos que todavía están en la industria y que realizan tareas, mayoritariamente, no rutinarias o que difícilmente pueden ser sustituidas por una serie de instrucciones o código. Al contrario de lo que cabría esperar, nuestros resultados sugieren que la participación de las tareas rutinarias en la agricultura solo ha aumentado en el tiempo, lo que apunta a una baja adopción de tecnologías basadas en la computación en comparación con otros sectores dentro de la economía chilena.

Palabras clave: Agricultura, automatización, Chile, rutinización, TIC.

\section{References}

Acemoglu, D., \& Autor, D. (2011). Skills, Tasks and Technologies: Implications for Employment and Earnings. In O. Ashenfelter \& D. Card (Eds.), Handbook of Labor Economics (Vol. 4B, pp. 1043-1171). Elsevier Science \& Technology.

Almeida, R.K., Fernandes, A.M., \& Viollaz, M. (2020). Software Adoption, Employment Composition, and the Skill Content of Occupations in Chilean Firms. Journal of Development Studies, 56(1), 169-185. https://doi.org/10.1080/002203 88.2018.1546847

Anríquez, G., Foster, W., Melo, O., Subercaseaux, J.P., \& Valdés, A. (2016). Evidencia y desafios para el empleo estacional en la fruticultura en Chile. Centro de Políticas Públicas UC.

Anríquez, G., \& López, R. (2007). Agricultural growth and poverty in an archetypical middle income country: Chile 1987-2003. Agricultural Economics, 36(2), 191-202. https://doi. org/10.1111/j.1574-0862.2007.00198.x

Autor, D., \& Dorn, D. (2013). The growth of lowskill service jobs and the polarization of the US Labor Market. American Economic Review, 103(5), 1553-1597. https://doi.org/10.1257/ aer.103.5.1553

Autor, D., Katz, L.F., \& Krueger, A.B. (1998). Computing Inequality: Have Computers Changed the Labor Market? The Quarterly Journal of Economics, 113(4), 1169-1213.

Autor, D., Levy, F., \& Murnane, R. (2003). The Skill Content of Recent Technological Change: An
Empirical Exploration. The Quarterly Journal of Economics, 118(4), 1279-1333.

Bravo, J., Garcia, A., \& Schlechter, H. (2019). Mercado Laboral Chileno para la Cuarta Revolución Industrial (No. 59).

CNP. (2018). Formación de competencias para el trabajo en Chile.

Fleming, D.A., Abler, D.G., \& Goetz, S.J. (2010). Agricultural trade and poverty in Chile: a spatial analysis of product tradability. Agricultural Economics, 41(6), 545-553. https://doi.org/10.1111/ j.1574-0862.2010.00468.x

Foster, W., \& Valdés, A. (2006). Chilean Agriculture And Major Economic Reforms: Growth, Trade, Poverty And The Environment. Région et Développement, 1(23), 28.

Frey, C.B., \& Osborne, M.A. (2017). The future of employment: How susceptible are jobs to computerisation? Technological Forecasting and Social Change, 114, 254-280. https://doi. org/10.1016/j.techfore.2016.08.019

Goos, M., \& Manning, A. (2007). Lousy and Lovely Jobs: The Rising Polarization of Work in Britain. The Review of Economics and Statistics, 89(1), 118-133.

ILO. (2012). The International Standard Classification of Occupations (ISCO-08).

INE. (2018). Clasificador Chileno de Ocupaciones CIUO 08.CL.

Kekezi, O., \& Boschma, R. (2021). Returns to migration after job loss - The importance of job match. Environment and Planning A, O(0), 1-21. https:// doi.org/10.1177/0308518X211004577 
Lopez, R.E., \& Anriquez, G. (2004). Poverty and Agricultural Growth: Chile in the 1990s (No. 8532016-56098). EJADE: Electronic Journal of Agricultural and Development Economics. https:// doi.org/10.22004/ag.econ.12013

Mihaylov, E., \& Tijdens, K.G. (2019). Measuring the Routine and Non-Routine Task Content of 427 Four-Digit ISCO-08 Occupations. SSRN Electronic Journal. https://doi.org/10.2139/ ssrn.3389681

OECD. (2019). How's Life in the Digital Age?: Opportunities and Risks of the Digital Transformation for People's Well-being.

OIT. (2005). Cuadros de correspondencia CIUO88CIUO08. https://www.ilo.org/public/spanish/bu$\mathrm{reau} / \mathrm{stat} /$ isco/isco08/index.htm

Pérez, R., \& Valdés, A. (2019). Análisis de la evolución y desempeño agroexportador de Chile, 2000-2017.

Pérez, R., Valdés, A., \& Foster, W. (2020). Empleo y distribución de los ingresos de los trabajadores agrícolas en Chile 1998-2017.

Reijnders, L.S.M., \& de Vries, G.J. (2018). Technology, offshoring and the rise of non-routine jobs. Journal of Development Economics, 135(August), 412-432. https://doi.org/10.1016/j.jdeveco.2018.08.009
Rivera, T. (2019). Efectos de la automatización en el empleo en Chile. Revista de Análisis Económico, 34(1), 3-49. https://doi.org/10.4067/s071888702019000100003

Rose, D.C., \& Chilvers, J. (2018). Agriculture 4.0: Broadening Responsible Innovation in an Era of Smart Farming. Frontiers in Sustainable Food Systems, 2, 87. https://doi.org/10.3389/ fsufs.2018.00087

Spitz $\square$ Oener, A. (2006). Technical Change, Job Tasks, and Rising Educational Demands: Looking outside the Wage Structure. Journal of Labor Economics, 24(2), 235-270. https://doi. org/10.1086/499972

Valderas, R., Meyer, M., \& González, R. (2011). Crecimiento económico en el sector agropecuario-silvícola a nivel nacional y regional en el período 1996-2008. Idesia (Arica), 29(2), 119-129. https://doi.org/10.4067/S071834292011000200016

Valdés Alonso, A., Foster, W., \& Rivera, R. (2008). Evolución del ingreso agrícola real en América Latina, 1990-2005: Evidencia en base a cuentas nacionales y encuestas de hogares. Revista Española de Estudios Agrosociales y Pesqueros, 2008(218), 71-98. 